\title{
Enhancement of microphase ordering and mechanical properties of supramolecular hydrogen-bonded polyurethane networks
}

Article

Accepted Version

Hermida-Merino, D., O'Driscoll, B., Hart, L. R., Harris, P. J., Colquhoun, H. M., Slark, A. T., Prisacariu, C., Hamley, I. W. and Hayes, W. (2018) Enhancement of microphase ordering and mechanical properties of supramolecular hydrogenbonded polyurethane networks. Polymer Chemistry, 9 (24). pp. 3406-3414. ISSN 1759-9954 doi:

https://doi.org/10.1039/C8PY00604K Available at https://centaur.reading.ac.uk/77600/

It is advisable to refer to the publisher's version if you intend to cite from the work. See Guidance on citing.

To link to this article DOI: http://dx.doi.org/10.1039/C8PY00604K

Publisher: Royal Society of Chemistry

All outputs in CentAUR are protected by Intellectual Property Rights law, including copyright law. Copyright and IPR is retained by the creators or other copyright holders. Terms and conditions for use of this material are defined in the End User Agreement. 


\section{CentAUR}

Central Archive at the University of Reading

Reading's research outputs online 


\section{Enhancement of Microphase Ordering and Mechanical Properties of Supramolecular Hydrogen-Bonded Polyurethane Networks}

Daniel Hermida-Merino, ${ }^{\text {a† }}$ Ben O’Driscoll, ${ }^{\mathrm{a}}$ Lewis R. Hart, ${ }^{\mathrm{a}}$ Peter J. Harris, ${ }^{\mathrm{b}}$ Howard M. Colquhoun, ${ }^{\mathrm{a}}$ Andrew T. Slark, ${ }^{\mathrm{c}}$ Cristina Prisacariu, ${ }^{\mathrm{d} \ddagger}$ Ian W. Hamley, ${ }^{\mathrm{a}}$ and Wayne Hayes ${ }^{\mathrm{a}^{*}}$

${ }^{a}$ Department of Chemistry, University of Reading, Whiteknights, Reading, RG6 6AD, UK, Email: w.c.hayes@reading.ac.uk.

${ }^{b}$ Electron Microscopy Laboratory, University of Reading, Whiteknights, Reading, RG6 6AD, UK

${ }^{c}$ Henkel Adhesive Technologies, Wood Lane End, Hemel Hempstead, HP2 4RQ UK

${ }^{d}$ Petru Poni Institute of Macromolecular Chemistry of the Romanian Academy, Aleea Grigore Chica Voda, Nr. 41 A, Iasi 700487, Romania

\footnotetext{
† Present address: DUBBLE CRG, BM26, ESRF-The European Synchrotron, Netherlands Organization for Scientific Research, 6 rue Jules Horowitz, 38043, Grenoble, France.

This paper is dedicated to our dear friend and colleague, Dr Cristina Prisacariu, who sadly passed away during preparation of this manuscript.
}

The improvement of the mechanical properties of supramolecular polymer networks is currently receiving significant interest both within academic and industrial circles in order to enable the application of these desirable stimuli-responsive materials in real world situations. In this study, structural units within phase separated supramolecular polyurethane (SPU) networks have been changed to assess the role of the hard segment composition on the mechanical characteristics of the resultant materials. Notably, increasing the degrees of conformational freedom within the hard segment component of a SPU was found to improve the phase separation and as a consequence also increase the storage modulus of the polymer network. Specifically, replacing 4,4'-methylene diphenyl diisocyanate with 4,4'-dibenzyl diisocyanate within a SPU improved the packing efficiency of the isocyanate derived hard segments and improved the physical properties of the supramolecular polymer network. This study utilised a combination of SAXS, WAXS and AFM analysis to assess the degree of crystallinity within the hard segment component of the polymer network whilst rheological analysis was used to establish the mechanical characteristics of the polymers.

\section{Introduction}

First disclosed over 80 years ago, ${ }^{1}$ polyurethanes (PUs) are now a widely utilised class of materials which have traditionally been accessed via reaction of polyols with polyisocyanates ${ }^{2-}$ 
5 to yield a versatile and diverse range of materials. As a result of their facile synthesis and attractive physical properties, PUs have found use as thermoplastic, thermosetting and elastomeric materials ${ }^{6}$ in applications including adhesives, protective coatings, foams, fibers, elastomers and medicine. ${ }^{7-10}$ Numerous polyols have been harnessed as building blocks, however, from the range of commercially available isocyanates, methylene diphenyl diisocyanate (MDI) has found the most extensive use on account of its attractive chemistries and relatively low toxicity. ${ }^{11,12}$

A recent development in PU chemistries has been the investigation of supramolecular polyurethane (SPU) networks ${ }^{13-18}$ which are able to self-assemble through weak non-covalent interactions. ${ }^{19-27}$ These materials are attractive on account of their thermo-reversible characteristics. $^{28-32}$ Gooch and co-workers have reported ${ }^{33}$ SPU-based elastomers which assemble through triple hydrogen bonding interactions and provide access to different degrees of crystallinity. By altering the feed ratio of the hetero-complementary polymers the mechanical properties were also enhanced. Gao et al. have described ${ }^{34}$ the synthesis and properties of PU 'cationomers' with an imidazolium-diol based chain extender which demonstrated a modulus of approximately $180 \mathrm{MPa}$ as a result of enhanced immiscibility between the hard and soft segments. Burattini and co-workers have studied ${ }^{35}$ the intramolecular interactions between chain-folding polyimide and telechelic polyurethane featuring electronically complementary pyrenyl end groups. The supramolecular blend formed by a combination of hydrogen bonding and $\pi-\pi$ stacking interactions produced a healable material with a tensile modulus of $0.3 \mathrm{MPa}$ and a modulus of toughness of $510 \mathrm{MPa}$. More recently, Feula et $a l .{ }^{36}$ have developed a well-defined hydrogen bonded SPU with a low dissociation temperature which permits healing at physiological temperatures. The biocompatible synthetic skin was able to fully recover its mechanical performance after healing for 1 hour at $37^{\circ} \mathrm{C}$.

It has been reported ${ }^{15}$ that the mechanical properties of chain extended PUs are influenced by the chemistries of the polymer which control the phase separation between rigid hard and flexible soft segments of the polymer architecture. Furthermore, the improvement in mechanical properties ${ }^{37}$ and resulting surface hydrophobicity ${ }^{38}$ have been attributed to phase separation in the polymer matrix. For example, Yilgör and co-workers have investigated the local packing of the urea moieties in segmented PUs in order to obtain high degrees of microphase separation. ${ }^{13,14,39-41}$ Furthermore, phase separation can be promoted by using an apolar soft segment with low surface energies such as polydimethylsiloxane (PDMS). ${ }^{42-44}$ Incorporation of a range of hard segments as chain extenders has also led to the generation of 
tuneable thermo-reversible materials. ${ }^{28,29,45}$ Prisacariu and co-workers have reported ${ }^{46}$ recently the use of 4,4'-dibenzyl diisocyanate (DBDI) in PU synthesis as alternative to MDI. DBDI features an ethylene linkage between the aromatic isocyanate moieties which permits free rotation about the linker, resulting in optimal alignment of the urethane or urea containing motifs between polymer chains. In principle this more flexible linkage enhances the ordering of the hard segments in linear PUs. ${ }^{47}$ Indeed, the use of the more flexible diisocyanate (DBDI) in covalent and chain-extended PUs $\left(M_{\mathrm{n}}=60,000-120,000 \mathrm{~g} \mathrm{~mol}^{-1}\right)$ has enhanced the ordering of the hard segments with appreciable improvement in the mechanical properties relative to MDI-derived analogues. ${ }^{46,48-55}$

Herein we report the synthesis and properties of a novel series of self-assembled low molecular weight $\left(>12,000 \mathrm{~g} \mathrm{~mol}^{-1}\right)$ and phase separated supramolecular polyurethanes which feature DBDI derived hard segments with a view to improving both the thermal and mechanical characteristics of supramolecular polymers. The effect of incorporating a flexible ethylene linkage into the urethane/urea component of these self-assembling materials is reported and evaluated.

\section{Results and Discussion}

In order to understand the role of the diisocyanate-derived hard segment within the selfassembled polymer network, SPUs 1-4 (Scheme 1 and Table 1) with 4,4'-DBDI residues were synthesised by first end-capping the apolar polybutadiene 5 (Krasol LBH 2000, $M_{\mathrm{W}}=2020$ gmol $^{-1}$ ) mid-block, with DBDI 6 to afford the pre-polymer 7.9.56 


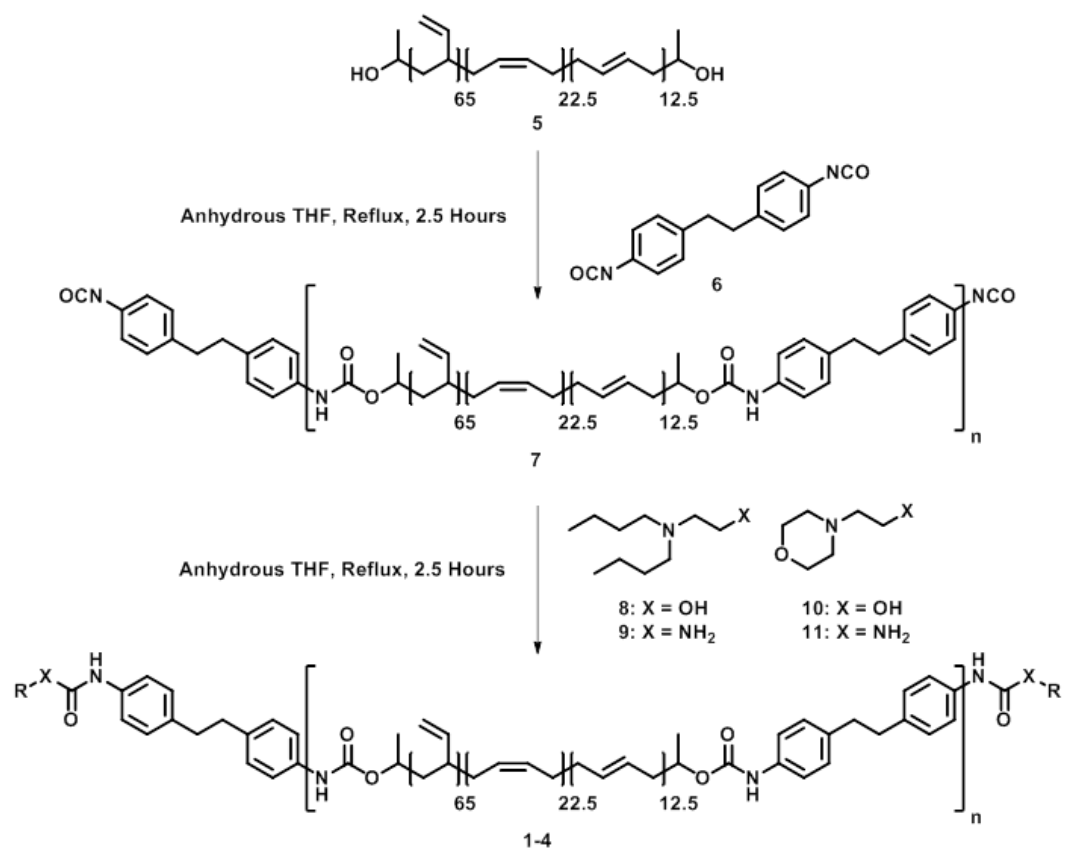

Scheme 1: Synthesis of Polyurethanes 1-4 with DBDI 6 derived hard segments.

To allow sole focus on the physical properties arising as a consequence of the hard segment, end-groups were selected with predictable contributions to the self-assembly process, thus allowing comparison to analogues derived from MDI. ${ }^{26,29,46,57-60}$ Termination of the prepolymer 7 was successfully achieved by addition of either derivatives containing morpholine or dibutylamine motifs (8-11) with amino or hydroxyl functionalities, respectively (Table 1). The chosen end-groups have previously been reported in structurally similar SPUs containing 4,4'-MDI derived hard segments. The SPUs reported by Woodward et al. ${ }^{29}$ were shown to be weakly hydrogen bond, or indeed not at all in the case of the dibutylamine motif. Details of the materials and methods, as well as full spectroscopic characterisation for the SPUs 1-4 can be found in the supporting information.

Table 1: End group and yields from the synthesis of SPUs 1-4.

Compound


To investigate the packing of hard segments between SPU chains containing both DBDI and MDI derived hard segments and the efficiency of intermolecular hydrogen bonding, energy minimised molecular models (Figure 1) were generated. A single repeat unit of the polyol soft segment capped by two DBDI or MDI moieties with terminal methyl units (hard segments) was modelled using Cerius ${ }^{2}$ software and the Dreiding II $^{61}$ force field. Examination of the models reveals the packing within DBDI derived hard segments is more efficient (Figure 1a and 1b). Close contacts forming linear hydrogen bonds of lengths 2.3-2.6 $\AA$ between the hydrogen bond donors ( $\mathrm{NH}$ of urethane/urea) and the hydrogen bond acceptors (carbonyl oxygen) were observed. These distances are in good agreement with hydrogen bond lengths measured in crystals. ${ }^{62,63}$ The polymers are also observed to be well-ordered in the DBDI derived SPU array as demonstrated by examination of the polymer chains, end on. Visually, the phenyl rings of the DBDI motifs were rotated into the same plane as a result of the increased flexibility of the ethylene linkage. When the MDI derived SPU model was subjected to the same constraints, less efficient packing was observed in both the hard and soft segments as well as increased hydrogen bonding $\left(\mathrm{NH}^{\cdots} \mathrm{O}\right)$ distances (2.3-2.8 $\AA$ ) between the polymer chains (Figure 1c and 1d). It was also noted that the polymer chains are contracted in length in the model of the MDI derived polymers when compared to the DBDI derived analogue, possibly related to the packing efficiency of the isocyanate moiety.

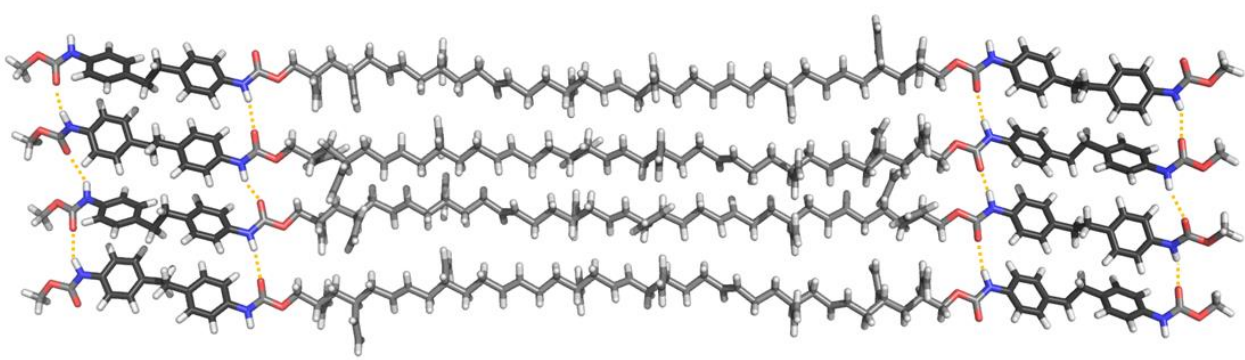

c

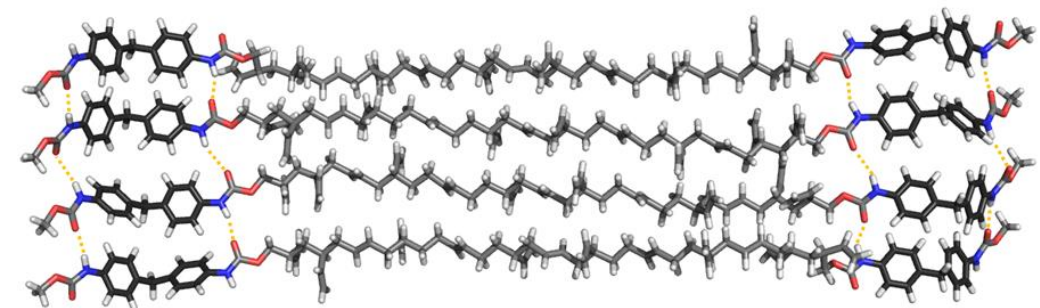

b

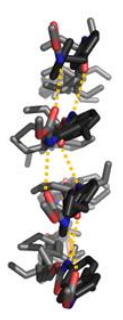

d

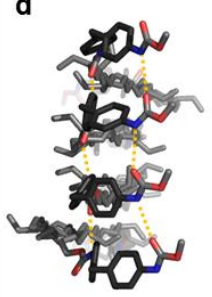

Figure 1: To scale, energy minimised molecular models of a DBDI derived oligomer and $\mathbf{b}$ chain-end on view of the same molecular assembly showing more efficient stacking when compared to analogous MDI derivatives (c $\& \mathbf{d})$. 
Variable temperature FT-IR spectroscopic analysis was conducted on the SPUs 1-4 (Figure 2) and revealed a thermo-responsive behaviour similar to structurally related MDI analogues. ${ }^{26,29}$ A strong absorbance for both the free $\left(1730 \mathrm{~cm}^{-1}\right)$ and hydrogen-bonded $\left(1710 \mathrm{~cm}^{-1}\right)$ urethane groups ${ }^{64}$ was observed in all SPUs at room temperature, arising from the urethane bonds in the pre-polymer in addition to the end-groups in polymers $\mathbf{1}$ and $\mathbf{2}$. The ordered hydrogen bonded urea band at $c a .1640 \mathrm{~cm}^{-1}$ was observed to be the predominant absorbance within the urea vibration modes for polymers $\mathbf{3}$ and $\mathbf{4}$ in addition to the hydrogen bonded urethane absorbance. The intensity of both the urethane and urea absorbance bands were seen to diminish with increased temperature for all SPUs 1-4, as a result of dissociation of the hydrogen bonded network. However, after heating to $120^{\circ} \mathrm{C}$, hydrogen bonding was still present above $50 \%$ in all cases. This effect may be attributed to the more efficient packing in the hard segments, resulting in increased hydrogen bond strength and crystallinity. After approximately 30 minutes at room temperature, full recovery of the relative percentage of hydrogen bonding was observed within the SPUs 1-4 as determined spectroscopically. The recovery of the relative percentage of hydrogen bonding over time demonstrates the thermoreversible nature of the SPUs and is in good agreement with our previous studies for analogues SPUs previously reported by Woodward et al. ${ }^{29}$ Therefore, it is proposed that the presence of a DBDI derived moiety in the SPUs (1-4) improves the efficiency of packing within the polymer network, whilst retaining the hydrogen bonding characteristics of the urethane/urea functional groups. 

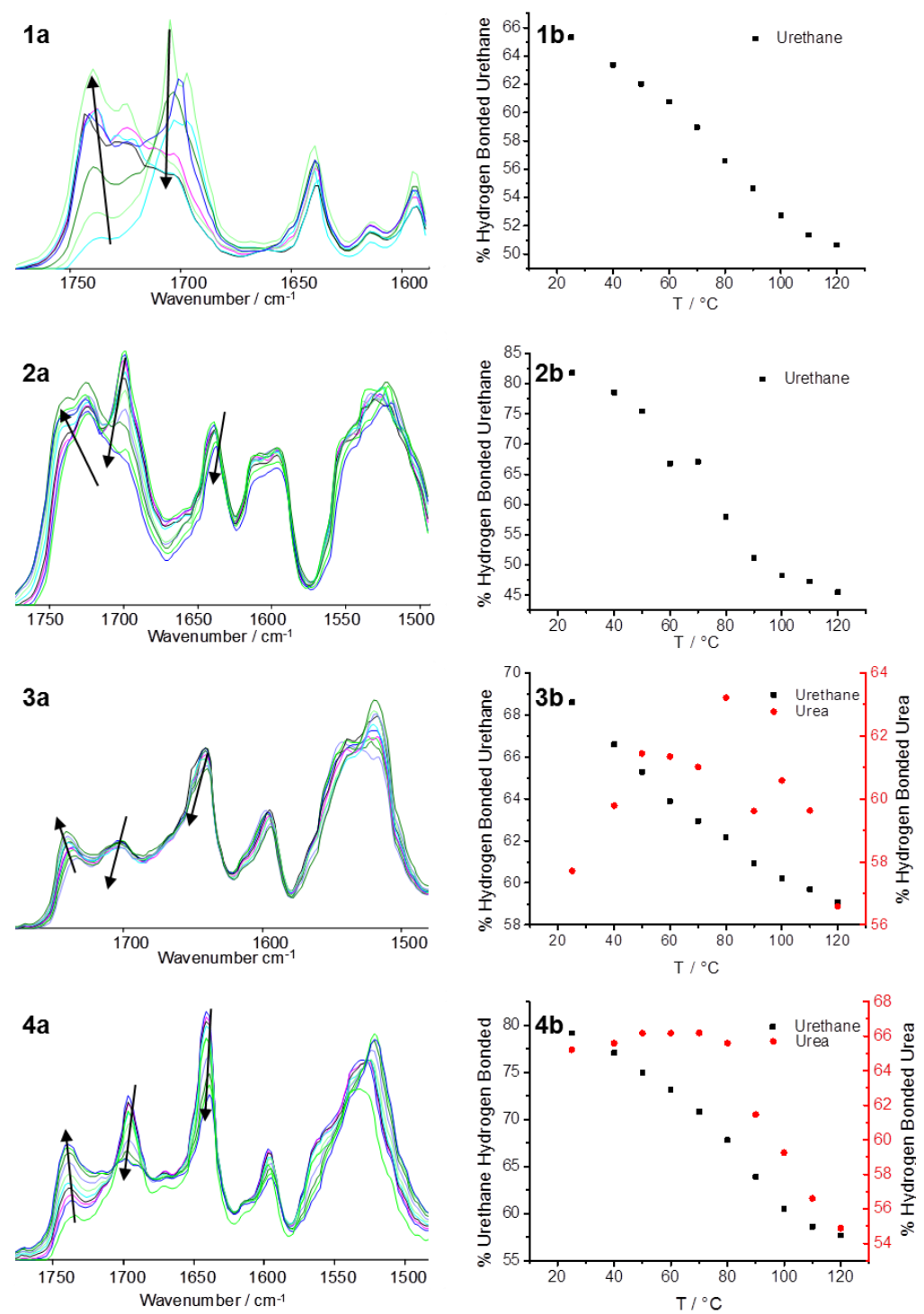

Figure 2: a) VT-FTIR spectra $\left(25-120^{\circ} \mathrm{C}\right)$ of DBDI-derived SPUs 1-4 and b) hydrogen bonded urethane and urea content for the DBDI SPUs (1-4).

\section{Morphological Analysis}

To assess the crystallinity within the hard segments of the polymers obtained with DBDI (18.0 wt\% of structural components in the polymer which includes the DBDI unit) and compare their morphology to that of MDI analogues ${ }^{26,29}$ (17.4-18.3 wt\% hard segment), the SPUs 1-4 were probed via SAXS, WAXS and AFM analyses.

Temperature dependant SAXS experiments (Figure 3) revealed that the DBDI derived linker indeed promotes organisation of the hard segments as a result of the ethylene bridging residue's increased rotational freedom. Microphase separation is observed for all SPUs 1-4 as indicated by the reflection at $0.047 \AA^{-1}$ for the morpholine derivatives $(2 \& 4)$ and $0.067 \AA^{-1}$ for the 
corresponding dibutylamine analogues $(\mathbf{1} \& \mathbf{3})$. The domain spacing within the DBDI derivatives was thus determined to be $c a .13 .2 \mathrm{~nm}$ for morpholine derivatives (urethane $\mathbf{2}$ and urea 4 analogues) and $c a .9 .0 \mathrm{~nm}$ for both dibutylamine derivatives (urethane $\mathbf{1}$ and urea $\mathbf{3}$ analogues). These domain spacings are approximately twice those observed for the MDI derived analogues (MDI-dibutylamine $=4.31 \mathrm{~nm}$ and $5.12 \mathrm{~nm}$ and MDI-morpholine $=5.20 \mathrm{~nm}$ and $5.70 \mathrm{~nm}),{ }^{26,28,29}$ suggesting that the SPU chains are able to adopt a more extended configuration permitted by enhanced stacking of the DBDI units. Interestingly, the SAXS profile of SPU 3 possesses two reflections centred at $0.067 \AA^{-1}(9 \mathrm{~nm})$ and $0.11 \AA^{-1}(5.7 \mathrm{~nm})$ which is a novel pattern for supramolecular polyurethane-urea systems of this type. ${ }^{26,28,29}$ The second order SAXS peak $(\mathrm{q} \sqrt{3})$ corresponds to hexagonal packing of cylinders within the micro-domains as a result of association of the urethane-urea motifs which are allowed to form without disruption from the dibutylamine end-groups. These results suggest a higher degree of microphase separation compared to analogues materials with MDI hard segments. The thermoresponsive behaviour of the SPUs 1-4 were investigated by heat/cool cycle between $-60{ }^{\circ} \mathrm{C}$ and $70{ }^{\circ} \mathrm{C}$ conducted at $5{ }^{\circ} \mathrm{C} \min ^{-1}$. The temperature response of the microphase separation exhibited an analogous trend to systems reported previously. ${ }^{26,29}$ Upon heating from $-60{ }^{\circ} \mathrm{C}$, the thermal history of the material was initially removed and an equilibrium reached as demonstrated by an increase in the intensity of the SAXS peak at $0.067 \AA^{-1}$. The intensity of the SAXS peak then decreases at $c a .70{ }^{\circ} \mathrm{C}$, indicating the phase mixing of the hard and soft segments via disruption of the hydrogen bonding interactions. Upon cooling, the intensity of the SAXS peak at $0.067 \AA^{-1}$ increases once again as a result of the hydrogen bonding network being restored. This trend further supports the thermo-responsive properties of the SPUs 1-4 reported by IR spectroscopy. 

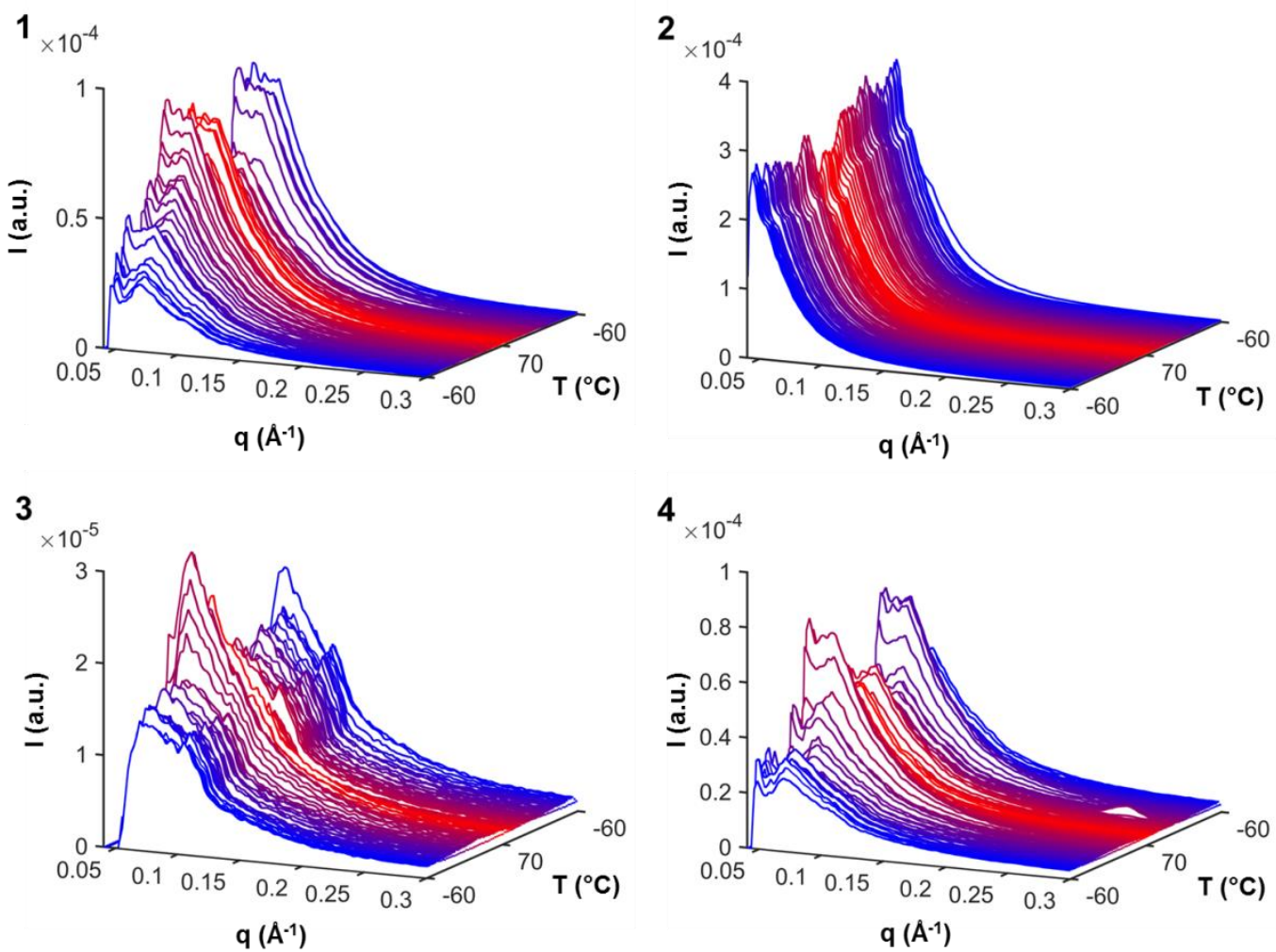

Figure 3: Variable temperature SAXS analysis of 1-4. The samples were heated at $5{ }^{\circ} \mathrm{C} \min ^{-1}$ between $-60{ }^{\circ} \mathrm{C}$ (nearest) and $70{ }^{\circ} \mathrm{C}$ before cooling to $-60{ }^{\circ} \mathrm{C}$ (furthest).

WAXS studies were performed to investigate the nanostructure of DBDI segments in the SPUs. In principle, the conformation adopted by the DBDI linker should enable 'crystalline' like micro-domains to form in the bulk as a result of the ordered hydrogen bonding and aromatic $\pi-\pi$ stacking interactions as indicated in the SAXS profiles of the SPUs (Figure 3). Notably, the WAXS profiles (Figure 4) of the DBDI derivative SPUs 1-4 feature several reflections on the broad amorphous scattering signal, especially in the case of SPU 2. Notably, the crystalline pattern corresponds to a urethane derivative which confirms the ordering potential of the DBDI linker. The reflections observed in the WAXS profiles correspond to association of the urethane/urea chain ends (4.5-4.7 $\AA$ ) in the polymer matrix, in excellent agreement with structurally related SPUs (4.6-4.7 ̊). ${ }^{29,64}$ Furthermore, the WAXS profiles of SPUs 1-4 all exhibit a broad shoulder at $c a .2 \theta=20^{\circ}$ within the crystalline region. These signals correspond to domain spacings of $3.5 \AA$, which strongly suggests $\pi-\pi$ stacking interactions between the aromatic motifs within the hydrogen bonding hard segments. ${ }^{26}$ This result along with the absence of these features in structurally related materials ${ }^{29}$ incorporating MDI further supports the hypothesis that the ethylene bridge provides greater rotational freedom allowing more efficient packing of the hard segments. 


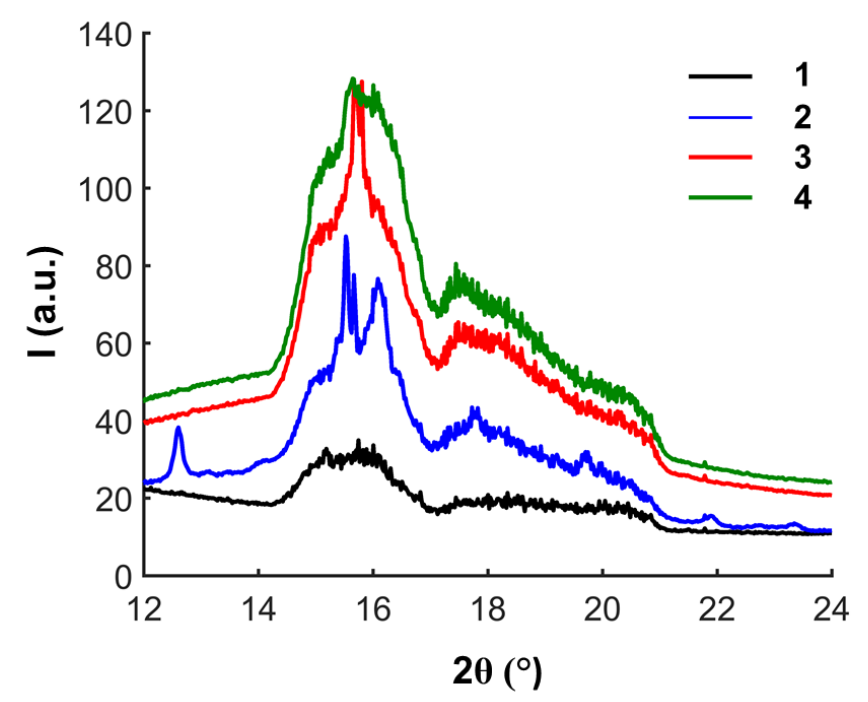

Figure 4: Comparison of WAXS profiles for DBDI-based SPUs (1-4).

The thermo-responsive dynamics of the 'crystalline' micro-domains was probed by VT-WAXS analysis to understand the thermally induced disruption of the hydrogen bonding interactions (Figure 5) within the hard segments. In agreement with the VT-SAXS experiments, the VTWAXS profiles follow a similar temperature trend and demonstrate the thermoreversibility of the ordering within these materials.
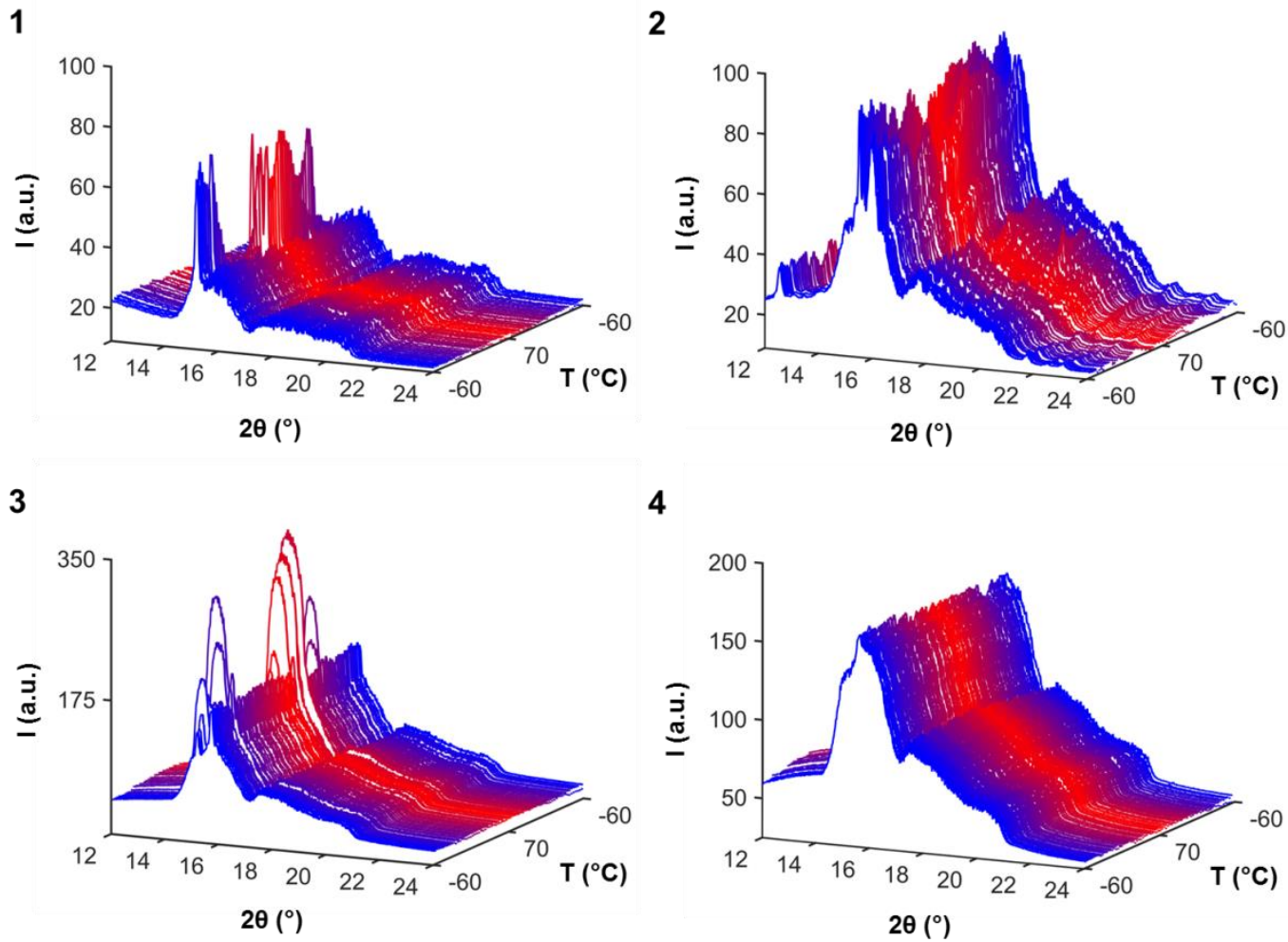

Figure 5: Variable temperature WAXS analysis of SPUs 1-4. The samples were heated at $5{ }^{\circ} \mathrm{C} \mathrm{min}^{-1}$ between $-60{ }^{\circ} \mathrm{C}$ and $70{ }^{\circ} \mathrm{C}$ over three cycles. 
To further analyse the self-assembly of the SPUs 1-4, AFM studies (Figure 6 and Figure S9) were carried out to visualize the changes in the morphology attained by the DBDI derived SPUs when compared to the MDI-based analogues. ${ }^{26,29}$ The ordered stacking of the DBDI linkers has been observed $^{46}$ to promote the packing of both urethane and urea moieties. As a result, the microphase separation of the DBDI supramolecular derivatives should favour alignment of the urea/urethane moieties within fibrillar aggregates. Remarkably, the all-urethane SPUs $\mathbf{1}$ and $\mathbf{2}$ are present as fibres with high aspect ratios (i.e. $c a .100 \mathrm{~nm}$ in length and $c a .10 \mathrm{~nm}$ in width). Increased phase mixing is observed in SPU $\mathbf{1}$ as a result of the relatively weak hydrogen bonds between urethane motifs (5.1 wt\% end groups in 1, comprising terminal DBDI unit and the covalently bound end-group). In contracts, SPU 2 forms more defined fibre like structures on account of association of the morpholine end-group (3.4 wt\% end group content) with the urethanes of the PU residues. Interestingly, spheres or cylinder like morphologies are observed in SPUs 3 and 4. SPU 3 gives rise to defined structures as a result of the relatively strong bifurcated hydrogen bonding interactions between urea moieties within the hard segments which are not disrupted by the dibutyl terminal-groups (4.2 wt\% end group content). In comparison, disruption to the hard segment assembly is observed in the morphology of SPU 4 as a consequence of the morpholine terminal group (3.8 wt\% end group content) hydrogen bonding to the urethane/urea groups. The resulting disruption in the hydrogen bonding network and decreased crystallinity results, however, in the formation of $3 \mathrm{D}$ structures as the morpholine residues allow interactions between self-assembled arrays. These observations from AFM imaging are in good agreement with the SAXS profiles obtained for the SPUs 1-4, where features $c a .9-13 \mathrm{~nm}$ were observed. Perhaps this is most clearly demonstrated in the case of SPU 3 which revealed a reflection at $9 \mathrm{~nm}$ which corresponds to the diameter of spheres or cylinders (Figure 6 [3]). 

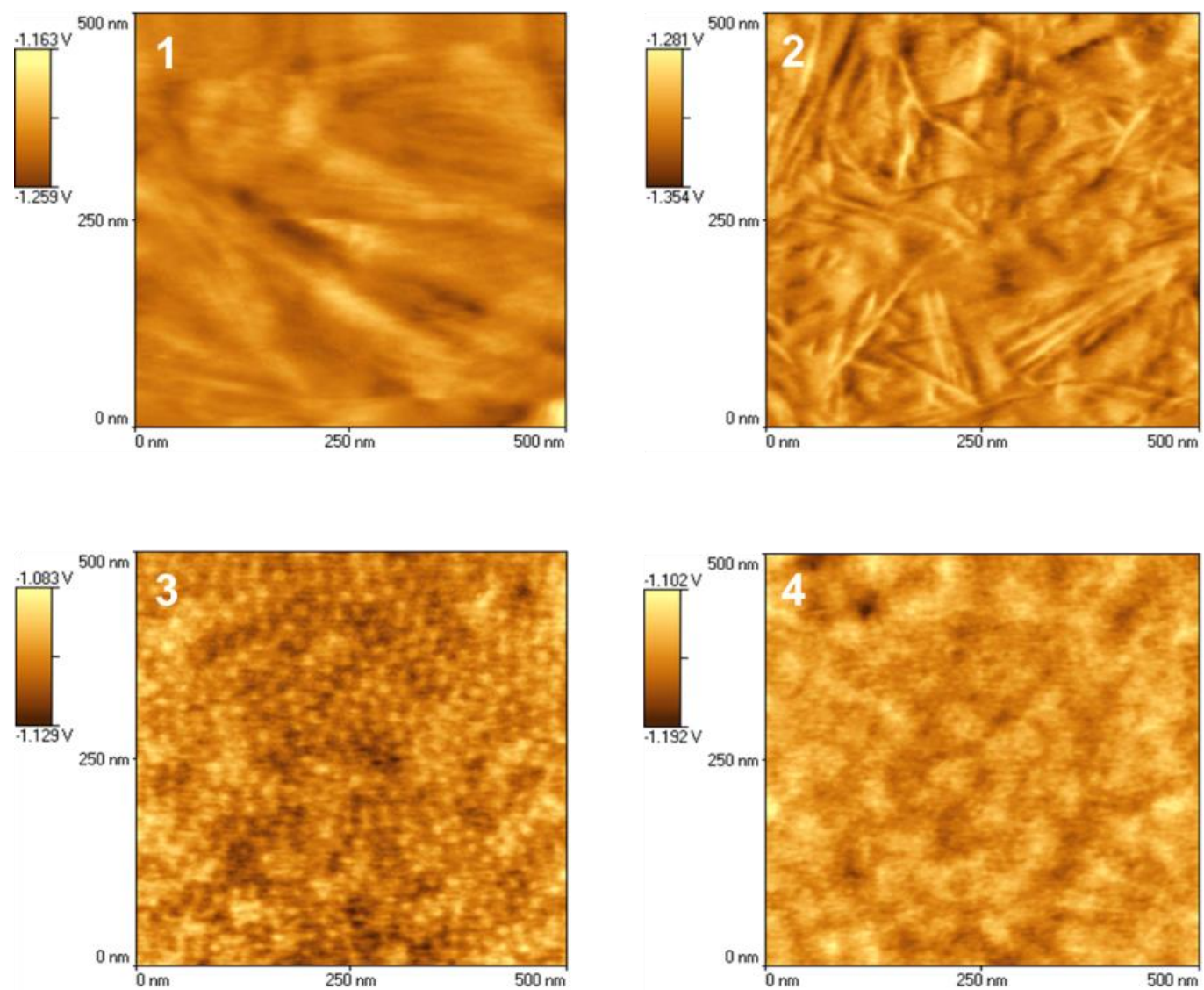

Figure 6: AFM phase micrographs of DBDI based SPUs 1-4.

\section{Rheological Analysis}

To probe the effect of hard segment composition $(18.0 \mathrm{wt} \%)$ on the mechanical properties of the SPUs, rheological analysis was undertaken. The storage modulus (G') for all DBDI derived materials was observed at $c a .10^{7} \mathrm{~Pa}$ which is approximately an order of magnitude greater than those observed for structurally related polymers containing MDI moieties ${ }^{26,29}$ with comparable molecular weights and polymeric composition. This observation provides strong evidence that the efficiency of packing within the hard segment is closely related to the mechanical properties of the SPUs. Interestingly, the storage moduli of SPUs 1-4 were approximately an order of magnitude greater when compared to supramolecular polymers which self-assemble through recognition motifs ${ }^{66,67}$ which possess association constants which are $10^{4} \mathrm{M}^{-1}$ larger than those reported herein. In addition, the storage moduli of SPUs 1-4 are also comparable to DBDI derived linear, high molecular weight PUs previously reported by Prisacariu et al..$^{50,52,53,55}$ This result can be attributed to the decrease of phase mixing of the hard and soft segments within the polymer architecture which is known $^{68}$ to improve the mechanical properties of the polymer. The plateau of the viscoelastic region is recorded at a higher modulus when compared 
to analogous SPUs. ${ }^{29}$ Furthermore, the sharper transition of both the storage and loss moduli at high temperature confirms the 'crystalline' nature of the micro-domains afforded. This melting transition also occurs over a narrow temperature range $\left(\mathrm{ca} .15^{\circ} \mathrm{C}\right)$ for the urethane derivatives $1 \& 2$ and $c a .35^{\circ} \mathrm{C}$ for the urea derivatives $3 \& 4$. Both temperature windows are significantly more defined than those observed for structurally related MDI analogues $\left(c a .75{ }^{\circ} \mathrm{C}\right){ }^{26,29}$ For all SPUs 1-4, the melting transition onset is also observed at a higher temperature $\left(70{ }^{\circ} \mathrm{C}\right)$ when compared to MDI analogues $\left(20{ }^{\circ} \mathrm{C}\right),{ }^{26,29}$ demonstrating a stiffer material at elevated temperatures as a result of enhanced packing between the polymer chains. These thermal characteristics could be considered an attractive feature for industrial applications with respect to materials processing and properties. The temperature difference at which the viscoelastic transition occurs as well as the magnitude of the plateau of the storage modulus, are consistent with the differences in ordering of the nano-domains produced by the DBDI derived linkers and the potential for the enhancement of the mechanical properties. The profile of $\tan \delta$ (Figure $7 b$ ) also corroborates the presence of a glass transition at higher temperatures (in excess of 80 $\left.{ }^{\circ} \mathrm{C}\right)$ which can be assigned to the hard segment phase within the polymer matrix.

a

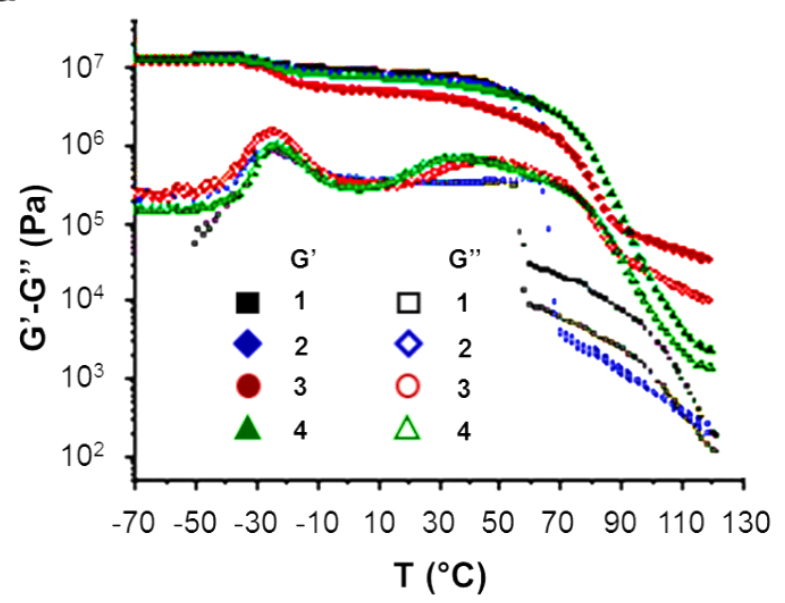

b

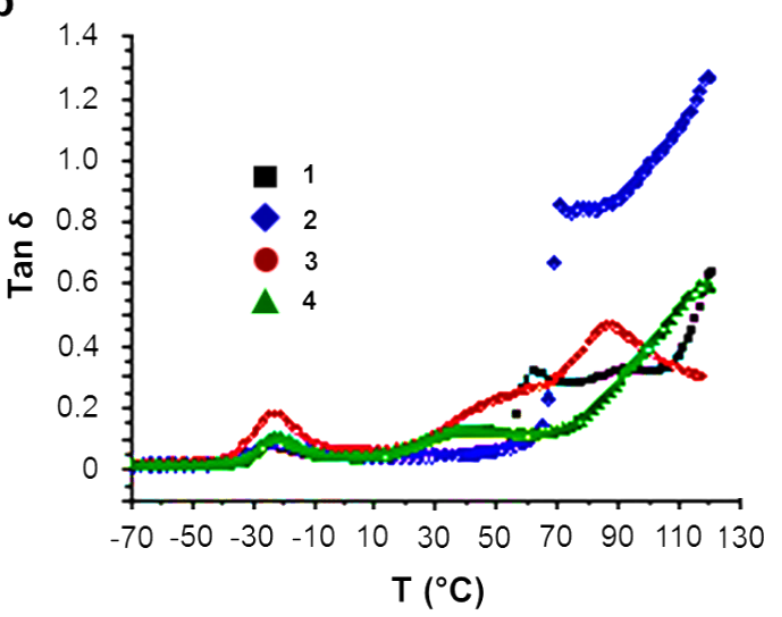

Figure 7: a) Thermal dependence of dynamic shear moduli for DBDI derived polymers 1-4. b) plot of $\tan \delta$ versus temperature for DBDI based SPUs 1-4.

\section{Conclusion}

The investigation of the use of diisocyanate DBDI within supramolecular polyurethanes 1-4 has revealed that packing of the hard segments leads to the improvement of the mechanical properties and thermal processing window of these supramolecular polymers when compared to analogues with less ordered MDI segments. Moreover, these materials offer comparable stiffness to chain-extended and high molecular weight PUs containing DBDI and other 
supramolecular polymers that are assembled through recognition motifs with higher association constants. Notably, the ordering effect of the DBDI derivatives led to well-defined structures such as fibres, spheres or cylinders, observed by AFM. Interestingly, the SAXS profile of $\mathbf{3}$ revealed two reflections is a novel SAXS pattern for a urethane-based supramolecular polymer which is consistent with the presence of well-defined microphase separated domains in the AMF images. The domain spacing of the DBDI derivatives $(9-13 \mathrm{~nm})$ revealed by SAXS, indicates that the DBDI derivatives polymers possess an extended configuration. Remarkably, the WAXS profiles showed a 'crystalline' like morphology that confirms the close packing of the hard segments. Variable temperature SAXS and WAXS analysis also demonstrated the thermo-reversibility of the ordering within the SPUs. The attractive rheological and thermal properties of the DBDI derived SPUs also provide scope for their use in industrial applications as a result of transitions observed in the narrow temperature range and higher temperatures. These results, when compared with the MDI derivatives, ${ }^{26,28,29}$ show the potential of the employment of DBDI for generating materials with improved mechanical properties.

\section{Acknowledgements}

The authors would like to thank Henkel Adhesive Technologies (post-graduate studentship for DHM), EPSRC (EP/N024818/1, post-doctoral research fellowship in support of LRH) and the University of Reading for financial support of this research. The authors would also like to acknowledge the University of Reading for access to analytical instrumentation within the Chemical Analysis Facility. Mr Oliver Balmford is also thanked for his insight in reproducing scattering data.

\section{References}

1 O. Bayer, W. Siefken, H. Rinke, L. Orthner, and H. Schild, DE728981, Ger. Pat. DRP, 1937, 728981.

2 W. Yu, M. Du, D. Zhang, Y. Lin and Q. Zheng, Macromolecules, 2013, 46, 73417351.

3 I. Lee and F. S. Bates, Macromolecules, 2013, 46, 4529-4539.

4 T. Saito, J. H. Perkins, D. C. Jackson, N. E. Trammel, M. A. Hunt and A. K. Naskar, RSC Adv., 2013, 3, 21832-21840.

$5 \quad$ P. Król, Prog. Mater. Sci., 2007, 52, 915-1015.

6 H.-W. Engels, H.-G. Pirkl, R. Albers, R. W. Albach, J. Krause, A. Hoffmann, H. 
Casselmann and J. Dormish, Angew. Chemie - Int. Ed., 2013, 52, 9422-9441.

I. Yilgor and E. Yilgor, Polym. Rev., 2007, 47, 487-510.

D. K. Chattopadhyay and K. V. S. N. Raju, Prog. Polym. Sci., 2007, 32, 352-418.

J. Courtois, I. Baroudi, N. Nouvel, E. Degrandi, S. Pensec, G. Ducouret, C. Chanéac,

L. Bouteiller and C. Creton, Adv. Funct. Mater., 2010, 20, 1803-1811.

Z. Pan, L. Yu, N. Song, L. Zhou, J. Li, M. Ding, H. Tan and Q. Fu, Polym. Chem., 2014, 5, 2901-2910.

11 D. Randall and S. Lee, Eds., The Polyurethanes Book, Wiley-Blackwell UK, 1st Edit., 2003.

12 Z. S. Petrovic and J. Ferguson, Prog. Polym. Sci., 1991, 16, 695-836.

13 T. F. A. A. De Greef, M. M. J. J. Smulders, M. Wolffs, A. P. H. J. H. J. Schenning, R. P. Sijbesma, E. W. Meijer, T. F. A. De Greef and C. Counterpart, Chem. Rev., 2009, 109, 5687-5754.

14 M. C. Stuparu, A. Khan and C. J. Hawker, Polym. Chem., 2012, 3, 3033-3044.

15 K. A. Houton and A. J. Wilson, Polym. Int., 2015, 64, 165-173.

16 B. Isare, S. Pensec, M. Raynal and L. Bouteiller, Comptes Rendus Chim., 2016, 19, $148-156$.

17 K. A. Houton, G. M. Burslem and A. J. Wilson, Chem. Sci., 2015, 6, 2382-2388.

18 A. Gooch, N. S. Murphy, N. H. Thomson and A. J. Wilson, Macromolecules, 2013, 46, 9634-9641.

19 X. Callies, C. Fonteneau, C. Véchambre, S. Pensec, J. M. Chenal, L. Chazeau, L. Bouteiller, G. Ducouret and C. Creton, Polymer, 2015, 69, 233-240.

20 K. Melia, B. W. Greenland, D. Hermida-Merino, L. R. Hart, I. W. Hamley, H. M. Colquhoun, A. T. Slark and W. Hayes, React. Funct. Polym., 2018, 124, 156-161.

21 A. Feula, A. Pethybridge, C. R. Siviour, C. P. Buckley, I. W. Hamley and W. Hayes, Macromolecules, 2015, 48, 6132-6141.

22 L. R. Hart, S. Li, C. Sturgess, R. Wildman, J. R. J. R. Jones and W. Hayes, ACS Appl. Mater. Interfaces, 2016, 8, 3115-3122.

23 A. Feula, X. Tang, I. Giannakopoulos, A. M. Chippindale, I. Hamley, F. Greco, C. P. Buckley, C. R. Siviour and W. Hayes, Chem. Sci., 2016, 7, 4291-4300.

24 D. M. Wood, B. W. Greenland, A. L. Acton, F. Rodriguez-Llansola, C. A. Murray, C. J. Cardin, J. F. Miravet, B. Escuder, I. W. Hamley and W. Hayes, Chem. - A Eur. J., 2012, 18, 2692-2699.

25 B. C. Baker, C. L. Higgins, D. Ravishankar, H. M. Colquhoun, G. C. Stevens, F. Greco, B. W. Greenland and W. Hayes, ChemistrySelect, 2016, 1, 1641-1649.

D. Hermida-Merino, A. Feula, K. Melia, A. T. Slark, I. Giannakopoulos, C. R. Siviour, C. P. Buckley, B. W. Greenland, D. Liu, Y. Gan, P. J. Harris, A. M. Chippindale, I. W. Hamley and W. Hayes, Polymer, 2016, 107, 368-378.

27 D. Hermida-Merino, M. Belal, B. W. Greenland, P. Woodward, A. T. Slark, F. J. Davis, G. R. Mitchell, I. W. Hamley and W. Hayes, Eur. Polym. J., 2012, 48, 1249 1255.

28 D. Hermida-Merino, A. T. Slark, H. M. Colquhoun, W. Hayes and I. W. Hamley, Polym. Chem., 2010, 1, 1263-1271.

29 P. Woodward, D. Hermida-Merino, B. W. Greenland, I. W. Hamley, Z. Light, A. T. Slark, and W. Hayes, Macromolecules, 2010, 43, 2512-2517.

30 C. B. St Pourcain and A. C. Griffin, Macromolecules, 1995, 28, 4116-4121.

31 M. C. Kuo, R. J. Jeng, W. C. Su and S. A. Dai, Macromolecules, 2008, 41, 682-690.

32 J.-M. Lehn, Chem. Soc. Rev., 2007, 36, 151-160.

33 A. Gooch, C. Nedolisa, K. A. Houton, C. I. Lindsay, A. Saiani and A. J. Wilson, Macromolecules, 2012, 45, 4723-4729. 
34 R. Gao, M. Zhang, S. W. Wang, R. B. Moore, R. H. Colby and T. E. Long, Macromol. Chem. Phys., 2013, 214, 1027-1036.

35 S. Burattini, D. Hermida-Merino, W. Weng, J. Seppala, H. M. Colquhoun, W. Hayes, M. E. Mackay, I. W. Hamley and S. J. Rowan, J. Am. Chem. Soc., 2010, 132, 1205112058.

36 A. Feula, X. Tang, I. Giannakopoulos, A. M. Chippindale, I. W. Hamley, F. Greco, C.

P. Buckley, C. R. Siviour and W. Hayes, Chem. Sci., 2016, 7, 4291-4300.

37 A. Mishra, B. P. Das Purkayastha, J. K. Roy, V. K. Aswal and P. Maiti, J. Phys. Chem. C, 2012, 116, 2260-2270.

38 K. Wei, L. Wang and S. Zheng, Polym. Chem., 2013, 4, 1491-1501.

39 S. Das, D. F. Cox, G. L. Wilkes, D. B. Klinedinst, I. Yilgor, E. Yilgor and F. L. Beyer, J. Macromol. Sci. Part B Phys., 2007, 46, 853-875.

40 P. R. Laity, J. E. Taylor, S. S. Wong, P. Khunkamchoo, K. Norris, M. Cable, G. T. Andrews, A. F. Johnson and R. E. Cameron, Polymer, 2004, 45, 5215-5232.

41 J. P. Sheth, D. B. Klinedinst, G. L. Wilkes, I. Yilgor and E. Yilgor, Polymer, 2005, 46, 7317-7322.

42 E. Yilgor, I. Yilgor and E. Yurtsever, Polymer, 2002, 43, 6551-6559.

43 D. J. Buckwalter, D. L. Inglefield, J. S. Enokida, A. G. Hudson, R. B. Moore and T. E. Long, Macromol. Chem. Phys., 2013, 214, 2073-2082.

44 L. M. Pitet, A. H. M. Van Loon, E. J. Kramer, C. J. Hawker and E. W. Meijer, ACS Macro Lett., 2013, 2, 1006-1010.

45 Y. Ni, F. Becquart, J. Chen and M. Taha, Macromolecules, 2013, 46, 1066-1074.

46 C. Prisacariu, R. H. Olley, A. A. Caraculacu, D. C. Bassett and C. Martin, Polymer, 2003, 44, 5407-5421.

47 A. A. Caraculacu, I. Agherghinei, C. Prisacariu and V. Cozan, J. Macromol. Sci. Part A - Chem., 1990, 27, 1547-1570.

48 C. Prisacariu, E. Scortanu and C. P. Buckley, Int. J. Polym. Anal. Charact., 2009, 14, 527-539.

49 C. Prisacariu, E. Scortanu and P. C. Buckley, in Proceedings of the World Congress on Engineering, 2008, vol. II, pp. 1468-1471.

50 C. Prisacariu, E. Scortanu, B. Agapie, V. A. Prisacariu and S. Coseri, Polym. Int., 2013, 62, 1600-1607.

51 C. Prisacariu, E. Scortanu, S. Coseri and B. Agapie, Int. J. Polym. Anal. Charact., 2013, 18, 154-161.

52 C. Prisacariu, E. Scortanu, I. Stoica, B. Agapie and V. Barboiu, Polym. J., 2011, 43, 613-620.

53 C. Prisacariu, E. Scortanu, A. Airinei, B. Agapie, M. Iurzhenko and Y. P. Mamunya, Procedia Eng., 2011, 10, 446-454.

54 C. Guo, L. Zhou and J. Lv, J. Appl. Polym. Sci., 2011, 122, 3544-3550.

55 C. Prisacariu, E. Scortanu and B. Agapie, Procedia Eng., 2011, 10, 984-989.

56 P. Woodward, A. Clarke, B. W. Greenland, D. Hermida-Merino, L. Yates, A. T. Slark, J. F. Miravet, and W. Hayes, Soft Matter, 2009, 5, 2000-2010.

57 C. Prisacariu and E. Scortanu, High Perform. Polym., 2008, 20, 117-125.

58 C. Prisacariu, C. P. Buckley and A. A. Caraculacu, Polymer, 2005, 46, 3884-3894.

59 C. Prisacariu, E. Scortanu, G. E. Hitruc and A. A. Caraculacu, Rev. Roum. Chim., 2007, 52, 415-422.

60 D. Hermida-Merino, M. Belal, B. W. Greenland, P. Woodward, A. T. Slark, F. J. Davis, G. R. Mitchell, I. W. Hamley and W. Hayes, Eur. Polym. J., 2012, 48, 12491255.

61 S. L. Mayo, B. D. Olafson and W. A. Goddard, J. Phys. Chem., 1990, 94, 8897-8909. 
62 W. Fuller, J. Phys. Chem., 1959, 63, 1705-1717.

63 S. Subramanian and M. J. Zaworotko, Coord. Chem. Rev., 1994, 137, 357-401.

64 L. Ning, W. De-Ning and Y. Sheng-Kang, Polymer, 1996, 37, 3045-3047.

65 F. Lortie, S. Boileau, L. Bouteiller, C. Chassenieux, B. Demé, G. Ducouret, M. Jalabert, F. Lauprêtre and P. Terech, Langmuir, 2002, 18, 7218-7222.

66 J. H. K. Ky Hirschberg, F. H. Beijer, H. A. van Aert, P. C. M. M. Magusin, R. P. Sijbesma and E. W. Meijer, Macromolecules, 1999, 32, 2696-2705.

67 B. Folmer, R. P. Sijbesma, R. M. Versteegen, J. A. J. van der Rijt and E. W. Meijer, Adv. Mater., 2000, 12, 874-878.

68 J. Zheng, R. Ozisik and R. W. Siegel, Polymer, 2006, 47, 7786-7794. 